\title{
External Dacryocystorhinostomy with and Without Suturing the Posterior Mucosal Flaps
}

\author{
Gazmend Kaçaniku ${ }^{1}$, Ilir Begolli ${ }^{2}$ \\ Eye Clinic, University Clinical Center of Kosovo, Prishtina, Republic of Kosovo ${ }^{1}$ \\ National Institute of Public Health of Kosovo, Prishtina, Republic of Kosovo ${ }^{2}$ \\ Corresponding author: Gazmend Kaçaniku, Associate Professor ULPIANA E-30 C-3/5. 10000 Prishtina, Republic of Kosovo. Tel.: \\ +37744122324. E-mail: gazmendk58@yahoo.com
}

\begin{abstract}
Purpose: To evaluate the outcome of the external dacryocystorhinostomy with and without suturing the posterior mucosal flaps. Methods: This study included 106 patients with lacrimal drainage system disorders who underwent the external dacryocystorhinostomy. Fifty four patients (Group A) underwent external dacryocystorhinostomy with suturing anterior and posterior flaps of the lacrimal sac and nasal mucosa, and the results obtained were compared with those of another series of 52 patients (Group B) where dacryocystorhinostomy was performed with suturing only the anterior flaps, whereas posterior mucosal flaps were excised. Results: The success rate was evaluated by lacrimal patency to irrigation and relief of epiphora. Patency achieved in groups A and B was $94.4 \%$ and $96.2 \%$, respectively. There was no statistically significant difference in success rate between the groups. Conclusion: Our study suggests that external dacryocystorhinostomy with suturing anterior and posterior flaps have no advantage over dacryocystorhinostomy with suturing only anterior flaps. Anastomosis by suturing only anterior flaps and excision of the posterior flaps is easier to perform and may improve the success rate of external dacryocystorhinostomy.
\end{abstract}

Key words: External dacryocystorhinostomy, posterior mucosal flaps.

\section{INTRODUCTION}

The aims of dacryocstyrhinostomy (DCR) are twofold: to eliminate fluid and mucus retention within the lacrimal sac and prevent sac enlargement (as a mucocele) the latter leading to intermittent viscous ocular discharge - and to bypass the higher hydraulic resistance of the nasolacrimal duct, thereby increasing tear conductance and aiding the relief of epiphora. External DCR should establish a low-resistance drainage pathway between the conjunctival tear sac and the nasal cavity, by conversion of the lacrimal sac into part of the lateral nasal wall (1). In 1921, Dupuy-Dutemps and Bourguet (2) described the technique of external DCR. In this procedure, the lacrimal sac was incised, forming both anterior and posterior flaps, and then carefully anatomosed to the nasal mucosa. Numerous modifications of this surgical procedure have been introduced over the years for a better surgical outcome. The aim of this study was to evaluate the outcomes of the conventional external DCR with suturing posterior and anterior mucosal flaps and the modified technique of external DCR with suturing anterior flaps only.

\section{METHODS}

This study included 106 patients with lacrimal drainage system disorders. Fifty four patients (Group A) underwent external DCR with suturing anterior and posterior mucosal flaps, and the results obtained were compared with those of another series of 52 patients (Group B) where
DCR was performed with suturing only the anterior flaps, whereas posterior mucosal flaps were excised. Patients younger than 20 years old and those who had previous failed DCR were excluded from the study. All operations were performed under local anesthesia after mild sedation. For statistical analysis we used the Chi-squared test, T-test and Fisher's exact test.

\subsection{Surgical techniques}

The surgical procedures are basically the same up to the suturing the mucosal flaps. A straight $15 \mathrm{~mm}$ skin incision is placed on the flat area of the nose, beginning just above the level of the medial canthal tendon (MCT); and 10-12 $\mathrm{mm}$ nasal to the medial canthus. Following the skin incision, the orbicularis muscle is bluntly dissected down to the periosteum of the frontal process of the maxilla, and the anterior limb of the medial canthal tendon and the periosteum are exposed. The skin and the orbicularis muscle are raised medially and laterally with two blunt rake retractors or with four traction sutures of 4-0 silk. After that, the periosteum is incised, starting by disinsertion of the anterior limb of the MCT and continuing down the anterior lacrimal crest. The periosteum is raised widely, anteriorly alongside the nose and posteriorly to elevate the lacrimal sac laterally within the lacrimal sac fossa. The lacrimal fossa is exposed in its entirety. Then, an osteotomy, approximately $15 \times 15 \mathrm{~mm}$ wide, in the lateral nasal wall is created with dental drill and the nasal mucosa exposed. The bony window includes the entire anteri- 
or lacrimal crest, lacrimal fossa, and superomedial wall of the nasolacrimal canal. The next step is to fashion the mucosal flaps. A "00" Bowman probe is inserted through the inferior canaliculus into the lacrimal sac, tenting up the medial wall of the sac. The medial face of the sac is opened with a no.11 blade from the upper fundus down to the proximal nasolacrimal duct. The sac is opened by the full vertical extent to avoid mucous lakes.

A vertical incision is made in the lacrimal sac to create anterior and posterior flaps, about two-thirds anterior, one-third posterior. Same vertical incision is made in exposed nasal mucosa to create anterior and posterior flaps, about two-thirds anterior, one-third posterior.

Posterior mucosal flaps are sutured with three interrupted 6-0 Vicryl sutures with half-circle needle and tied in three knots. Union of the posterior flaps should overlap the posterior osteotomy edge.

Silicone intubations were performed in eleven cases with medial common canalicular obstruction.

Anterior mucosal flaps are sutured with three interrupted 6-0 Vicryl sutures, passing through the superior, middle and inferior edges of the flaps and tied in three knots with sufficient tension to prevent sagging of the flaps and to obstruct the internal ostium or scarring the posterior flaps anastomosis.

In the modified technique of external dacryocystorhinomy the posterior nasal and lacrimal sac flaps are excised. In this way we created an anastomosis by suturing only anterior flaps of the lacrimal sac and nasal mucosa.

Upon completion of the mucosal anastomosis, the surgical wound is closed in two layers. Deep tissues, including orbicularis and subcuticular layers, are closed with several interrupted 6-0 Vicryl sutures and skin with prolen 6-0 sutures. Follow-up examinations were scheduled in period of 18 months from the date of surgery. Surgery was considered successful when the patient had no epiphora and a patent lacrimal passage on irrigation.

\section{RESULTS}

By gender, the majority of treated patients 78 (73.6\%) were female, and 28 (26.4) were male. In the group A, 41 (76.0\%) patients were female and $13(24.0 \%)$ were male; while in the group B, 37 (71.2\%) patients were female and $15(28.8 \%)$ were male. Both groups have similar gender breakdown without significant difference $\left(\mathrm{X}^{2}\right.$ test $=0,113$; $\mathrm{p}=0,736)$.

By age, the mean age in the group A was a bit higher 47.0 years (range $23-65$ years) compared to 45.6 years (range 22-63 years) in the group B (Table 1). The age difference by groups was not considerable-there was no significant difference $(\mathrm{T}$ test $=0.695 ; \mathrm{p}>0.05)$.

The mean time of follow-up for both groups was 17.0 months (range 12 - 18 months). The mean time of follow-up for the group A was 16.9 $\pm 1.90 \mathrm{SD}$ months, whereas for the group B it was $17.1 \pm 1.8 \mathrm{SD}$ months (Table 2 ). The difference was not statistically significant ( $\mathrm{T}$ test $=-0.670$; $\mathrm{p}>0.05)$.

Lacrimal drainage system disorders included in this study were chronic dacryocystitis in 47 (44.3\%) cases, lacrimal fistula in 7 (6.6\%) cases, nasolacrimal duct obstruction in 41 cases $(38.7 \%)$, and medial common can-

\begin{tabular}{lcccccc}
\hline \multirow{2}{*}{$\begin{array}{l}\text { Age in } \\
\text { years }\end{array}$} & \multicolumn{2}{c}{ Group A } & \multicolumn{2}{c}{ Group B } & \multicolumn{2}{c}{ Total } \\
\cline { 2 - 7 } & No. & $\%$ & No. & $\%$ & No. & $\%$ \\
\hline $20-29$ & 4 & 7.4 & 5 & 9.6 & 9 & 8.4 \\
\hline $30-39$ & 10 & 18.5 & 11 & 21.1 & 21 & 19.9 \\
\hline $40-49$ & 16 & 29.7 & 15 & 28.9 & 31 & 29.2 \\
\hline $50-59$ & 19 & 35.2 & 18 & 34.6 & 37 & 35.0 \\
\hline $60+$ & 5 & 9.2 & 3 & 5.8 & 8 & 7.5 \\
\hline Total & 54 & 100.0 & 52 & 100.0 & 106 & 100.0 \\
\hline Xmax & 65 & - & 63 & - & 65 & - \\
\hline Xmin & 23 & - & 22 & - & 22 & - \\
\hline Xb & 47.0 & - & 45.6 & - & 46.3 & - \\
\hline SD & 10.8 & - & 10.8 & - & 10.8 & - \\
\hline VC & 22.9 & - & 23.7 & - & 23.3 & - \\
\hline
\end{tabular}

T test $=0.695 ; \mathrm{p}>0.05$

Table 1. Age distribution by groups

\begin{tabular}{lllllll}
\hline \multirow{2}{*}{$\begin{array}{l}\text { Time of fol- } \\
\text { low-up (months) }\end{array}$} & \multicolumn{2}{l}{ Group A } & \multicolumn{2}{l}{ Group B } & \multicolumn{2}{l}{ Total } \\
\cline { 2 - 8 } & No. & $\%$ & No. & $\%$ & No. & $\%$ \\
\hline 12 & 5 & 9.3 & 4 & 7.7 & 9 & 8.5 \\
\hline 15 & 10 & 18.5 & 7 & 13.4 & 17 & 16.0 \\
\hline 18 & 39 & 72.2 & 41 & 78.9 & 80 & 75.5 \\
\hline Total & 54 & 100.0 & 52 & 100.0 & 106 & 100.0 \\
\hline $\begin{array}{l}\text { Mean time of } \\
\text { follow-up }\end{array}$ & 16.9 & - & 17.1 & - & 17.0 & - \\
\hline SD & 1.9 & - & 1.8 & - & 1.9 & - \\
\hline VC & 11.5 & - & 10.5 & - & 11.0 & - \\
\hline
\end{tabular}

T test $=-0.670 ; \mathrm{p}>0.05$

Table 2 . The patients time of follow-up by groups

\begin{tabular}{lcccccc}
\hline $\begin{array}{l}\text { Lacrimal drain- } \\
\begin{array}{l}\text { age system dis- } \\
\text { orders }\end{array}\end{array}$ & \multicolumn{2}{c}{ Group A } & \multicolumn{2}{c}{ Group B } & \multicolumn{2}{c}{ Total } \\
\cline { 2 - 7 } & No. & $\%$ & No. & $\%$ & No. & $\%$ \\
\hline $\begin{array}{l}\text { Chronic dacryo- } \\
\text { cystitis }\end{array}$ & 24 & 44.5 & 23 & 44.2 & 47 & 44.3 \\
\hline $\begin{array}{l}\text { Lacrimal fistula } \\
\text { Nasolacrimal } \\
\text { duct obstruction }\end{array}$ & 21 & 7.4 & 3 & 5.8 & 7 & 6.6 \\
\hline $\begin{array}{l}\text { Medial common } \\
\text { canalicular ob- } \\
\text { struction }\end{array}$ & 5 & 9.2 & 6 & 11.5 & 11 & 10.4 \\
\hline \begin{tabular}{l} 
Total \\
\hline
\end{tabular} & 54 & 100.0 & 52 & 100.0 & 106 & 100.0 \\
\hline
\end{tabular}

$\mathrm{X}^{2}$ test $=0,242 ; \mathrm{p}=0.970$

Table 3. Lacrimal drainage system disorders by groups

\begin{tabular}{lcccccc}
\hline \multirow{2}{*}{ Complications } & \multicolumn{2}{c}{ Group A } & \multicolumn{2}{c}{ Group B } & \multicolumn{2}{c}{ Total } \\
\cline { 2 - 7 } & No. & $\%$ & No. & $\%$ & No. & $\%$ \\
\hline $\begin{array}{l}\text { Intraoperative } \\
\text { hemorrhage }\end{array}$ & 5 & 9.3 & 3 & 5.8 & 8 & 7.6 \\
\hline $\begin{array}{l}\text { Laceration of the } \\
\text { nasal mucosa }\end{array}$ & 3 & 5.5 & 2 & 3.8 & 5 & 4.7 \\
\hline Uneventful & 46 & 85.2 & 47 & 90.4 & 93 & 87.7 \\
\hline Total & 54 & 100.0 & 52 & 100.0 & 106 & 100.0
\end{tabular}

$\mathrm{X}^{2}$ test $=0,673 ; \mathrm{p}=0.714$

Table 4. Intraoperative complications by groups

alicular obstruction in $11(10.4 \%)$ cases. Cases of chronic dacryocystitis (44.3\%) and nasolacrimal duct obstruction (38.7\%) predominated among operated patients within this research (Table 3). There was no significant difference between the treatment groups $\left(\mathrm{X}^{2}\right.$ test $\left.=0,242 ; \mathrm{p}=0.970\right)$. 
Intraoperatively the surgery was uneventful in 93 (87.7\%) out of 106 cases, while in 8 cases (7.6\%) we had hemorrhage and in 5 cases (4.7\%) laceration of the nasal mucosa (Table 4). The difference between the groups was not statistically significant $\left(\mathrm{X}^{2}\right.$ test $\left.=0,673 ; \mathrm{p}=0.714\right)$.

The postoperative complication-closure of the anastomosis-in the group B was in 2 cases (3.8\%), and in 3 cases $(5.5 \%)$ in the group A. With the relevant Chi-squaredtest the difference was not statistically significant $\left(\mathrm{X}^{2}\right.$ test $=0,172 ; \mathrm{p}=0.678$ ).

The success rate was evaluated by lacrimal patency to irrigation and relief of epiphora. Patency was achieved in 101 cases $(95.3 \%)$, whereas epiphora recurred in 5 cases (4.7\%). By groups, patency in the group B was in 50 cases (96.2\%) a bit higher compared to the group A where it was in 51 cases (94.5\%). Recurrence of epiphora in the group A was in 3 cases (5.5\%), and in 2 cases (3.8\%) in the group B. Since in our study at least $20 \%$ of expected frequencies are less than 5, we used Fisher's exact test. The two-tailed P value equals 1.0000 . The association between groups and outcomes is considered to be statistically insignificant.

\section{DISCUSSION}

The success rate of external DCR has been reported between $90 \%$ and $100 \%$ depending on the surgeon's experience $(3,4,5,6,7)$. External DCR is a reliable but difficult surgical technique and requires considerable experience as well as operative time. To overcome the difficulties of external DCR and for a better surgical outcome, several authors have suggested different modifications of conventional external DCR. In this regard we presented our experience and success rate for two groups of external DCR with and without suturing the posterior flaps.

Anastomosis by suturing only anterior flaps and excision of the posterior flaps is easier to perform and simplifies the surgical procedure. On the other hand, suturing the posterior flaps often constitutes a difficulty and may take a considerable amount of time, particularly in the presence of bleeding during the surgery. We believe that a wide open posterior region into the nose is as good as posterior flaps and better than poorly created or sutured posterior flaps, which may actually block the nasal opening. Although it is simpler and easier to master the surgical technique, this procedure shows a success rate comparable to that obtained by more complex conventional external DCR. Dareshani et al. (8) compared the success rate in which they sutured anterior and posterior flaps in one group and left the posterior flaps un-sutured in the second group. The success rate in sutured group was $97.6 \%$ and 94.2 in the un-sutured group. Talpur et al. (9) reported success rate of $98.14 \%$ out of 54 procedures of conventional external DCR. Baldeschi et al. (10) anastomosed large and mobile anterior flaps of the lacrimal sac and nasal mucosa and passed sutures through the orbicularis muscle to elevate the flaps forward and did not suture posterior flaps with a success rate of $100 \%$. Elwan (11) reported a success rate of $90 \%$ with excision of posterior flaps and $85 \%$ with suturing. Serin et al. (12) reported that with posterior flap anastomosis success rate was 93.75\% and with resection it was $96.67 \%$. Khan et al. (13) reported success rate of $97.1 \%$ in DCR with suturing of the posterior flaps and $94.3 \%$ in DCR with excision of the posterior flaps.

\section{CONCLUSION}

Our study suggests that external dacrycystorhinostomy with suturing anterior and posterior flaps have no advantage over dacryocystorhinostomy with suturing only anterior flaps. Anastamosis by suturing only anterior flaps and excision of the posterior flaps is easier to perform and may improve the success rate of external dacryocystorhinostomy.

\section{CONFLICT OF INTEREST: NONE DECLARED}

\section{REFERENCES}

1. Hart RH, Powrie S, Rose GE. Primary External Dacryocystorhinostomy. In: Cohen AJ, Mercandetti M, Brazzo BG. ed. The Lacrimal System. New York, Springer, 2006: 127.

2. Dupuy-Dutemps L, Bourguet M. Procede plastique de dacryocystorhinostomie et ses results. Ann Ocul. 1921; 158: 241-261.

3. Iliff CE. A simplified dacryocystorhinostomy. Arch Ophthalmol. 1971; 85: 586-591.

4. McLachlan DL, Shannon GM, Flanagan JC. Results of dacryocystorhinostomy: analysis of the reoperations. Ophthalmic Surg. 1980; 11: 427-430.

5. Welham RAN, Wulc AE. Management of unsuccessful lacrimal surgery. Br J Ophthalmol. 1987; 71: 152-157.

6. Walland MJ, Rose GE. Factors affecting the success rate of open lacrimal surgery. Br J Ophthalmol. 1994; 78: 888-891.

7. Delaney YM, Khooshabeh R. External dacryocystorhinostomy for the treatment of acquired partial nasolacrimal obstruction in adults. Br J Ophthalmol. 2002; 86: 533-535.

8. Dareshani S, Niazi JH, Saeed M, et al. Dacryocystorhinostomy: Importance of anastomosis between Anterior and Posterior Flaps. Pak J Ophthalmol. 1996; 12: 129-131.

9. Talpur KI, Jatoi SM, Khan SA. Dacryocystorhinostomy - A Clinical Report of 54 cases. Pak J Ophthalmol. 1998; 14: 169-171.

10. Baldeschi L, Nardi M, Hintschich CR, Koornneef L. Anterior suspended flaps: a modified approach for external dacryocystorhinostomy. Br J Ophthalmol. 1998; 82: 790-792.

11. Elwan S. A randomized study comparing DCR with and without excision of the posterior mucosal flap. Orbit. 2003; 22: 7-13.

12. Serin D, Alagoz G, Karsloglu S, Celebi S, Kukner S. External Dacryocystorhinostomy: Double-Flap Anastomosis or Excision of the Posterior Flaps? Ophthalmic Plast Reconstr Surg. 2007; 23: 28-31.

13. Khan FA, Yaqub MA, Fayyaz M. The Importance of Excising or Suturing the Posterior Mucosal Flaps in External Dacryocystorhinostomy. Pak J Ophthalmol. 2010; 26: 69-72. 